\title{
Effect of Moderate Alcohol Consumption on Plasma Dehydroepiandrosterone Sulfate, Testosterone, and Estradiol Levels in Middle-Aged Men and Postmenopausal Women: A Diet-Controlled Intervention Study
}

Aafje Sierksma, Taisto Sarkola, C. J. Peter Eriksson, Martijn S. van der Gaag, ${ }^{*}$ Diederick E. Grobbee, Henk F. J. Hendriks

\begin{abstract}
Background: Moderate alcohol consumption is inversely associated with cardiovascular diseases. Changes in hormone levels might in part help explain the positive health effect. This study was performed to examine the effect of moderate alcohol consumption on plasma dehydroepiandrosterone sulfate (DHEAS), testosterone, and estradiol levels.

Methods: In a randomized, diet-controlled, crossover study, 10 middle-aged men and 9 postmenopausal women, all apparently healthy, nonsmoking, and moderate alcohol drinkers, consumed beer or no-alcohol beer with dinner during two successive periods of 3 weeks. During the beer period, alcohol intake equaled 40 and $30 \mathrm{~g}$ per day for men and women, respectively. The total diet was supplied and had essentially the same composition during these 6 weeks. Before each treatment there was a 1 week washout period, in which the subjects were not allowed to drink alcoholic beverages. At the end of each of the two experimental periods, fasting blood samples were collected in the morning.

Results: Moderate alcohol consumption increased plasma DHEAS level by $16.5 \%$ (95\% confidence interval, $8.0-24.9)$, with similar changes for men and women. Plasma testosterone level decreased in men by $6.8 \%$ (95\% confidence interval, $-1.0--12.5$ ), but no effect was found in women. Plasma estradiol level was not affected. Serum high-density lipoprotein cholesterol level increased by $11.7 \%$ (95\% confidence interval, 7.3-16.0), with similar changes for men and women. The overall alcohol-induced relative changes in DHEAS, testosterone, and estradiol correlated positively with the relative increase in high-density lipoprotein cholesterol (adjusted for the relative change in body weight); however, findings were only borderline significant for DHEAS and estradiol $(r$ $=0.44, p=0.08 ; r=0.32, p=0.21$; and $r=0.46, p=0.06$, respectively).

Conclusions: A protective effect of moderate alcohol consumption for cardiovascular disease risk may in part be explained by increased plasma DHEAS level.

Key Words: Alcohol, Dehydroepiandosterone Sulfate (DHEAS), Testosterone, Estradiol, HDL Cholesterol.
\end{abstract}

$\mathbf{M}$ ODERATE ALCOHOL CONSUMPTION is inversely associated with cardiovascular diseases (CVD) (Colditz et al., 1985; Grobbee et al., 1999; Stampfer et al., 1988). Mechanisms proposed to explain a positive health effect of moderate alcohol consumption involve prevention of atherogenesis through changes in

From the Department of Nutritional Physiology, TNO Nutrition and Food Research (AS, MSvdG, HFJH), Zeist, The Netherlands; Julius Center for Health Sciences and Primary Care, University Medical Center Utrecht (AS, DEG), Utrecht, The Netherlands; and Department of Mental Health and Alcohol Research, National Public Health Institute (TS, CJPE), Helsinki, Finland.

Received for publication October 30, 2003; accepted January 7, 2004.

Supported by the Dutch Foundation for Alcohol Research (SAR).

Reprint requests: Henk F. J. Hendriks, PhD, TNO Nutrition and Food Research, Department of Nutritional Physiology, PO Box 360, 3700 AJ Zeist, The Netherlands; Fax: +31 30 6944928; E-mail: hendriks@voeding.tno.nl. *Deceased.

DOI: 10.1097/01.ALC.0000125356.70824.81 lipoprotein metabolism (Hendriks et al., 1998; Van der Gaag et al., 1999), hemostasis (Dimmitt et al., 1998; Hendriks et al., 1994), and inflammation (Imhof et al., 2001; Koenig et al., 1999; Sierksma et al., 2002b).

There is accumulating evidence suggesting the involvement of sex hormones in atherogenesis. Studies suggest a protective effect of high levels of dehydroepiandrosterone sulfate (DHEAS) against atherosclerosis (Barrett-Connor et al., 1986; Feldman et al., 2001; Leowattana, 2001). This is further supported by an observed inverse correlation between DHEAS levels and pulse wave velocity (Ishihara et al., 1992) and carotid wall thickness (Bernini et al., 1999). An independent inverse association between levels of testosterone and aortic atherosclerosis in men aged 55 years and over has been reported (Hak et al., 2002). In addition, studies in older men have shown an inverse association between testosterone levels and aortic stiffness (Dockery et 
Table 1. Characteristics of the Volunteers Included in the Data Analysis

\begin{tabular}{|c|c|c|c|c|}
\hline \multirow[b]{2}{*}{ Age $(y r)$} & \multicolumn{2}{|c|}{ Men $(n=10)$} & \multicolumn{2}{|c|}{ Women $(n=9)$} \\
\hline & $55(6)$ & $45-64$ & $57(4)$ & 49-62 \\
\hline Body weight (kg) & $79.2(9.2)$ & $62.7-93.7$ & $74.0(7.3)$ & $66.0-85.1$ \\
\hline $\mathrm{BMI}\left(\mathrm{kg} / \mathrm{m}^{2}\right)$ & $24.9(2.2)$ & $20.1-28.6$ & $26.8(2.9)$ & $22.0-30.7$ \\
\hline Hemoglobin (mmol/liter) & $9.4(0.5)$ & $8.7-10.7$ & $8.5(0.4)$ & $7.7-9.3$ \\
\hline Triglycerides (mmol/liter) & $1.2(0.4)$ & $0.8-1.9$ & $0.9(0.4)$ & $0.5-1.6$ \\
\hline Total cholesterol (mmol/liter) & $6.2(1.1)$ & $4.5-7.6$ & $6.9(1.3)$ & $5.4-8.6$ \\
\hline HDL cholesterol (mmol/liter) & $1.5(0.4)$ & $0.9-2.3$ & $2.0(0.4)$ & $1.6-2.6$ \\
\hline LDL cholesterol (mmol/liter) & $4.3(0.9)$ & $2.9-5.8$ & $4.5(1.2)$ & $3.3-6.3$ \\
\hline ASAT (units/liter) & $25(5)$ & 19-34 & $19(3)$ & $15-24$ \\
\hline ALAT (units/liter) & $21(4)$ & $17-29$ & $14(3)$ & $10-19$ \\
\hline GGT (units/liter) & $22(7)$ & $11-34$ & $16(4)$ & $11-23$ \\
\hline Glucose (mmol/liter) & $5.4(0.5)$ & $4.9-6.3$ & $5.5(0.4)$ & $5.0-6.1$ \\
\hline
\end{tabular}

Values are expressed as mean (SD) and range.

BMI, body mass index; HDL, high-density lipoprotein; LDL, low-density lipoprotein; ASAT, aspartate aminotransferase; ALAT, alanine aminotransferase; GGT, $\gamma$-glutamyltransferase.

al., 2002) and intima-media thickness (Van den Beld et al., 2003). Premenopausal women may be protected from CVD, relative to men, due to high circulating estrogen levels (Matthews, 1992).

Changes in hormone levels may in part explain the health benefits of moderate alcohol consumption. Two long-term diet-controlled intervention studies in pre- and postmenopausal women showed increases in DHEAS and plasma estrogen/estrone sulfate levels after moderate alcohol intake (Dorgan et al., 2001; Reichman et al., 1993). Effects of alcohol on hormone levels may depend on age and gender (Orentreich et al., 1984; Zumoff et al., 1980). To further investigate the effect of moderate alcohol consumption on plasma DHEAS, testosterone, and estradiol levels and their correlation with alcohol-induced changes in highdensity lipoprotein (HDL) cholesterol, we performed an intervention study in both middle-aged men and postmenopausal women. Diet was controlled during the study, as nutrition might influence sex hormone variability (Tamimi et al., 2001; Ukkola et al., 2001).

\section{METHODS}

\section{Subjects}

The study was conducted at TNO Nutrition and Food Research (Zeist, The Netherlands). The trial was performed according to the ICH Guidelines for Good Clinical Practice, complied with the Declaration of Helsinki, and was approved by the TNO Medical Ethics Committee. Ten middle-aged men and 10 postmenopausal women, all nonsmoking, were recruited from the pool of volunteers of TNO Nutrition and Food Research and through an advertisement in a local newspaper. The volunteers received all information about the study (including aim; medical, ethical, and practical aspects; and insurance) by verbal briefing and received the same information in writing and subsequently signed for informed consent. Subjects were eligible if they fulfilled the following inclusion criteria: consumption of $\leq 28$ alcohol-containing beverages per week for men and $\leq 21$ for women, body mass index between 20 and $31 \mathrm{~kg} / \mathrm{m}^{2}$, and no family history of alcoholism. Subjects were healthy as indicated by the values of the prestudy laboratory tests, which all were within the normal range. In addition, they were healthy as indicated by their medical history and a physical examination by the medical investigator. The postmenopausal women did not have menses for at least a year, were not ovariectomized, and did not use hormone replacement therapy. One postmenopausal woman dropped out because of a treatment-unrelated cause. The remain- ing 19 subjects completed the study successfully. Characteristics of the study population are given in Table 1.

\section{Study Design}

The subjects entered an open randomized crossover trial consisting of two periods of 3 weeks. Five men and five women were randomly allocated to the sequence beer (Amstel Bier, Amsterdam, The Netherlands; 5 vol\% alcohol) followed by no-alcohol beer (Amstel Malt Bier, Amsterdam, The Netherlands; $<0.1 \mathrm{vol} \%$ alcohol). The other half of the subjects consumed no-alcohol beer first followed by beer. In this way, any bias due to the beverage order and a possible drift of variables over time was eliminated. There was a 1 week washout period before each treatment period in which participants were not allowed to drink alcoholic beverages, to limit possible carryover effects.

Four glasses of each beverage for men and three glasses of each beverage for women were consumed daily during the evening dinner. During the beer period, alcohol intake equaled 40 and $30 \mathrm{~g}$ per day for men and women, respectively. The total diet was supplied to exclude dietary confounding. Subjects consumed all foods at home, except for evening dinner, which was served at TNO Nutrition and Food Research, together with the beer or no-alcohol beer. Subjects were not allowed to eat or drink anything but the foods supplied, except for tap water and coffee (limited amount of creamer was supplied), and they were asked to maintain their habitual physical activity pattern.

We considered the energy provided by alcohol to be $19.6 \mathrm{~kJ} / \mathrm{g}$, assuming the net usable energy content of alcohol is $70 \%$ of the theoretically present 28 kJ/g (Rumpler et al., 1996; Westerterp, 1996). Taking this into account, no-alcohol beer contained approximately $90 \mathrm{~kJ} / 100 \mathrm{ml}$, and beer contained approximately $130 \mathrm{~kJ} / 100 \mathrm{ml}$. The source of energy in no-alcohol beer was almost $100 \%$ carbohydrates; in beer approximately $40 \%$ of energy was derived from carbohydrates and $60 \%$ of energy was derived from alcohol. The diets, including beer or no-alcohol beer, were comparable in such a way that the macronutrient composition and total energy were the same during the beer and no-alcohol beer period. The macronutrient composition of the diet was based on the national Dutch food consumption survey of 1998 (Anonymous, 1998). Diets during the beer and no-alcohol beer period consisted of approximately $17 \%$ energy from protein, $39 \%$ energy from fat, and $44 \%$ energy from carbohydrate, for both males and females. Daily energy requirement was estimated for each subject according to Schofield (1985). The diet was provided in nine different levels of energy intake per day; $7,8,9,10,11,12,13,14$, and $15 \mathrm{MJ}$, depending on the body weight of the subject. Body weight was determined every 3 or 4 days with the subjects wearing indoor clothing, without shoes, wallet, and keys. When a subject's body weight deviated more than $1.5 \mathrm{~kg}$ from his or her weight at the first experimental day, energy supply was adjusted $( \pm 1$ $\mathrm{MJ}$ ), without changing the macronutrient composition, to maintain body weight. Compliance to the protocol, physical adverse events, and medicine use were checked by a daily questionnaire. 


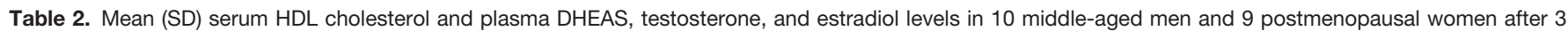
weeks consumption of beer and no-alcohol beer

\begin{tabular}{|c|c|c|c|c|}
\hline & \multicolumn{2}{|c|}{ Men $(n=10)$} & \multicolumn{2}{|c|}{ Women $(n=9)$} \\
\hline & Beer & No-alcohol beer & Beer & No-alcohol beer \\
\hline HDL cholesterol (mmol/liter) & $1.34(0.24)^{\star}$ & $1.18(0.16)$ & $1.70(0.33)^{\star}$ & $1.55(0.32)$ \\
\hline DHEAS (micromol/liter) & 4.0 (1.8)\# & $3.5(1.7)$ & $3.9(2.7)$ & $3.3(2.2)$ \\
\hline Testosterone (nmol/liter) & $15.3(3.6)^{\star}$ & $16.4(2.9)$ & $1.1(0.6)$ & $1.1(0.6)$ \\
\hline Estradiol (pmol/liter) & $66.6(11.7)$ & $65.2(8.9)$ & $28.2(16.3)$ & $28.0(13.0)$ \\
\hline
\end{tabular}

${ }^{*} p<0.05 ; \# p<0.001$; significantly different from the no-alcohol beer period.

\section{Blood Sampling and Analysis}

Fasting blood samples were collected in the morning after the last day of each experimental period. Blood was taken from the anticubital vein and collected in a tube containing citrate theophylline, adenosine, and dipyridamole and in a tube containing gel and clot activator (Becton Dickinson, Vacutainer Systems, Plymouth, UK). To obtain plasma and serum, the blood was centrifuged for $15 \mathrm{~min}$ at $2000 \times g$ and $4^{\circ} \mathrm{C}$, between 15 and $30 \mathrm{~min}$ after collection. All aliquots were stored at $-80^{\circ} \mathrm{C}$ until analysis.

Plasma DHEAS, testosterone, and estradiol levels were determined by standard radioimmunoassay reagent sets (Cout-a-Count DHEA-SO4 from Diagnostic Products Corporation, Los Angeles, CA, for DHEAS; Orion Diagnostica, Finland, for testosterone; Estradiol-2 from DiaSorin, Italy, for estradiol). Within- and between-assay variabilities were $7.8 \%(n$ $=12)$ and $7.9 \%(n=4)$ at the level of $4.5 \mu \mathrm{mol} /$ liter for plasma DHEAS (detection limit $0.05 \mu \mathrm{mol} /$ liter), $6.6 \%$ and $7.0 \%$ at the level of 0.96 nmol/liter $(n=10)$ for plasma testosterone (detection limit $0.1 \mathrm{nmol} /$ liter), and $9.0 \%(n=12)$ and $4.7 \%(n=4)$ at the level of $40 \mathrm{pmol} /$ liter for plasma estradiol (detection limit about 20 pmol/liter). Serum HDL cholesterol level was determined using an enzymatic method (Roche Diagnostics $\mathrm{GmbH}$, Mannheim, Germany), with a detection limit $0.08 \mathrm{mmol} /$ liter and a between-assay variability of about $3 \%$.

One hour after dinner on the last evening of each of the two experimental periods, blood was collected in tubes containing gel and clot activator (Becton Dickinson, Vacutainer Systems; airtight system) for blood alcohol concentration determination. Between 15 and 30 min after collection, blood was centrifuged for $15 \mathrm{~min}$ at $2000 \times g$ and $4^{\circ} \mathrm{C}$, and serum samples were stored at $-20^{\circ} \mathrm{C}$ until analysis. Blood alcohol concentrations were measured enzymatically (Roche Diagnostics $\mathrm{GmbH}$, Mannheim, Germany; within- and between-assay variability $0.5 \%$ and $2.3 \%$, respectively, detection limit $2.17 \mathrm{mmol} /$ liter).

All samples were analyzed in one run after the finish of the study. Staff members who conducted the laboratory analyses were blind to the group assignments.

\section{Statistical Methods}

Data were analyzed using the SAS statistical software package (SAS/ STAT version 6.12, SAS Institute, Cary, NC). The outcome measures were tested for normality. Treatment effects were assessed by analysis of variance, by use of general linear modeling, using as factors gender, beverage, and gender in combination with beverage. To test for carryover effects, the factor treatment order was also added to this model. We calculated 95\% confidence intervals (CI) according to Mood et al. (1974) and Finney (1964). Pearson correlation coefficients were computed to assess associations between relative alcohol-induced changes in sex hormones and HDL cholesterol. Two-sided $p$ values were considered statistically significant at $p \leq 0.05$.

\section{RESULTS}

The compliance to the supplied foods and drinks was good, and average body weight did not differ between beer and no-alcohol beer treatment periods (data not shown).
The overall mean blood alcohol concentration at $1 \mathrm{hr}$ after dinner with beer was $10.5 \mathrm{mmol} /$ liter (range $6.0-15.9 \mathrm{mmol} /$ liter), and the mean blood alcohol concentrations for men and women separately did not differ (11.2 [SD 3.0] and 9.7 [SD 1.6] $\mathrm{mmol} /$ liter, $p=0.20 ; t$ test). No carryover effects in outcome measures were seen.

\section{Plasma DHEAS level}

Plasma DHEAS level increased by $16.5 \%$ (95\% CI, 8.0-24.9) after beer consumption compared with noalcohol beer consumption. No gender differences were observed (Table 2).

\section{Plasma Testosterone Level}

Three weeks of beer consumption decreased plasma testosterone level by $6.8 \%$ in men $(95 \% \mathrm{CI},-1.0--12.5)$ compared with no-alcohol beer consumption. In women no effect on plasma testosterone level was observed (Table 2).

\section{Plasma Estradiol Level}

Plasma estradiol level was not affected after 3 weeks of beer consumption compared with no-alcohol beer consumption (Table 2).

\section{Serum HDL Cholesterol Level}

After 3 weeks of daily beer consumption, serum HDL cholesterol level significantly increased by $11.7 \%$ (95\% CI, 7.3-16.0) compared with no-alcohol beer consumption. Similar changes in men and women were observed (Table 2).

\section{Correlations Between Relative Alcohol-Induced HDL Cholesterol and Sex Hormone Changes}

The overall alcohol-induced relative changes in DHEAS, testosterone, and estradiol correlated positively with the relative increase in HDL cholesterol (adjusted for the relative change in body weight); however, these changes were only borderline significant for DHEAS and estradiol $(r=$ $0.44, p=0.08 ; r=0.32, p=0.21$; and $r=0.46, p=0.06$, respectively).

\section{DISCUSSION}

To our knowledge, this is the first diet-controlled study to examine the effects of moderate alcohol consumption on 
sex hormone levels in middle-aged men and postmenopausal women. A moderate daily dose of alcohol consumed with evening dinner increased plasma DHEAS level. Plasma testosterone level was decreased in men, and there was no effect on plasma estradiol level in both men and women. The volunteers were maintained on adequate nutritional regimen, and average body weight did not differ between beer and no-alcohol beer treatment periods. Consequently, the findings are unlikely to have been confounded by concomitant nutritional changes.

The increased plasma DHEAS level after moderate alcohol consumption agrees with observational data (Field et al., 1994; Kiechl et al., 2000; Ravaglia et al., 2002) and the two intervention studies in women (Dorgan et al., 2001; Reichman et al., 1993). With our study design, we cannot differentiate a chronic effect of moderate alcohol consumption from a possible acute effect of last evening drink. The increase in plasma DHEAS level in part could be a consequence of increased adrenal secretion and in part could be derived by ethanol-mediated inhibition of the isomerasedehydrogenase reaction of dehydroepiandrosterone (DHEA) to androstenedione (Frias et al., 2002). We could previously not disclose similar effects of moderate alcohol intake in a study in middle-aged men (Sierksma et al., 2002a). The reason for this discrepancy could be the shorter treatment period (17 days) and the more liberal dietary control (only evening dinner) compared with the current study. The increase in plasma DHEAS level in the current study would be compatible with an approximate $10 \%$ decrease in mortality from CVD (Barrett-Connor et al., 1986). However, doubts have been raised regarding the proposed inverse association between DHEAS and atherosclerosis risk (Kiechl et al., 2000). Some could not confirm this relationship (Barrett-Connor and Goodman-Gruen, 1995), whereas others found a positive rather than an inverse relationship (Johannes et al., 1999). Ravaglia et al. (2002) have suggested that low DHEAS levels are probably a nonspecific indicator of aging and health status. DHEAS is measured, because it is the stable form of DHEA. Despite the high correlation between DHEA and DHEAS levels (Nafziger et al., 1991) and their biological linkage, it cannot be ruled out that an association exists between DHEA and atherosclerosis risk, which could be missed by measuring its sulfated form. In addition, DHEA(S) may beneficially affect certain age-related disorders, such as cognitive impairment and dementia (Kalmijn et al., 1998; Watson et al., 1996). This would explain data suggesting that moderate alcohol consumption may protect against dementia (Mukamal et al., 2003; Ruitenberg et al., 2002).

Heavy alcohol intake decreases testosterone in men (Van Thiel and Lester, 1979; Ylikahri et al., 1974). This could reflect decreased plasma binding capacity and increased hepatic testosterone A-ring reductase activity (rate-limiting enzyme for the metabolism of testosterone in the liver) (Gordon et al., 1976) and/or an inhibited testosterone synthesis in the testis (Van Thiel and Lester, 1979).
Possibly these changes already occur with moderate alcohol consumption, explaining the decrease in plasma testosterone levels in the middle-aged men in our study. The clinical relevance of this change is unclear, as reproductive disturbances such as decreased libido, impotence, and infertility are found in long-term heavy alcohol drinkers (Van Thiel and Lester, 1979). In postmenopausal women, no effect of moderate alcohol intake on plasma testosterone level was found, which is in agreement with earlier increases in testosterone only in long-term female heavy drinkers (Cigolini et al., 1996; Pettersson et al., 1990; Välimäki et al., 1990, 1995). The testosterone reduction in men and the absence of an effect in women might well be a consequence of the last evening drink instead of a chronic effect of moderate alcohol consumption. Studies in women have shown that testosterone was elevated acutely by a low dose of alcohol (Eriksson et al., 1994; Sarkola et al., 2001).

The lack of effect of moderate alcohol consumption on plasma estradiol level is consistent with other studies (Cauley et al., 1989; Ginsburg et al., 1996; Hankinson et al., 1995; Newcomb et al., 1995). There are indications that the hops and barm in beer contain substances with estrogenic activity (Lapcík et al., 1998). Because both beer and noalcohol beer contain these substances, we assume that this will not have influenced the alcohol effect on plasma estradiol level. In women, substantial evidence exists for a protective role of endogenous sex hormones (Matthews, 1992). It has been discussed whether in postmenopausal women estrogen therapy may prevent the development of atherosclerosis (Grady et al., 2002; Hodis et al., 2003; Manson et al., 2003). Estradiol levels have been positively associated with breast cancer risk (Thomas et al., 1997). The lack of an alcohol-induced effect on plasma estradiol level in our study would suggest that moderate alcohol consumption does not operate through this pathway.

The alcohol-induced increase in serum HDL cholesterol level of about $12 \%$ in the present study is similar to that observed in other diet-controlled studies of our group (Van der Gaag et al., 1999, 2000). A 2\% increase in HDL cholesterol has been estimated to translate to a $2 \%$ to $4 \%$ decrease in coronary heart disease risk (Kinosian et al., 1995).

The correlations between the alcohol-induced relative changes in HDL cholesterol and sex hormones suggest that sex hormones may affect CVD risk indirectly via an effect on lipoproteins (Kiel et al., 1989; Okamoto, 1998; Zmuda et al., 1997).

\section{CONCLUSIONS}

Alcohol intake seems to decrease testosterone in men already at a moderate consumption level. In addition, the results of this randomized trial in healthy middle-aged men and postmenopausal women support the view that moderate intake of alcohol may increase plasma DHEAS level. This small endocrine effect of alcohol is consistent with a 
protective effect of moderate alcohol consumption with respect to CVD risk and possibly also the risk for dementia.

\section{ACKNOWLEDGMENTS}

We acknowledge all those involved in the conduct of the study and thank the volunteers for their enthusiastic participation.

\section{REFERENCES}

Anonymous (1998) Zo eet Nederland, 1998, Resultaten van de voedselconsumptiepeiling 1997-1998. Voedingscentrum, Den Haag.

Barrett-Connor E, Khaw KT, Yen SS (1986) A prospective study of dehydroepiandrosterone sulfate, mortality, and cardiovascular disease. N Engl J Med 315:1519-1524.

Barrett-Connor E, Goodman-Gruen D (1995) Dehydroepiandosterone sulfate does not predict cardiovascular death in postmenopausal women. The Rancho Bernardo Study Circulation 91:1757-1760.

Bernini GP, Sgro' M, Moretti A, Argenio GF, Barlascini CO, Cristofani R, Salvetti A (1999) Endogenous androgens and carotid intimal-medial thickness in women. J Clin Endocrinol Metab 84:2008-2012.

Cauley JA, Gutai JP, Kuller LH, LeDonne D, Powell JG (1989) The epidemiology of serum sex hormones in postmenopausal women. Am J Epidemiol 129:1120-1131.

Cigolini M, Targher G, Bergamo Andreis IA, Tonoli M, Filippi F, Muggeo M, De Sandre G (1996) Moderate alcohol consumption and its relation to visceral fat and plasma androgens in healthy women. Int J Obes Relat Metab Disord 20:206-212.

Colditz GA, Branch ALG, Lipnick RJ, Willett WC, Rosner B, Posner B, Hennekens CH (1985) Moderate alcohol and decreased cardiovascular mortality in an elderly cohort. Am Heart J 109:886-889.

Dimmitt SB, Rakic V, Puddey IB, Baker R, Oostryck R, Adams MJ, Chesterman CN, Burke V, Beilin LJ (1998) The effects of alcohol on coagulation and fibrinolytic factors: a controlled trial. Blood Coag Fibrinol 76:39-45.

Dockery F, Bulpitt CJ, Agarwal S, Rajkumar C (2002) Testosterone suppression in men with prostate cancer is associated with increased arterial stiffness. Aging Male 5:217-222.

Dorgan JF, Baer DJ, Albert PS, Judd JT, Brown ED, Corle DK, Campbell WS, Hartman TJ, Tejpar AA, Clevidence BA, Giffen CA, Chandler DW, Stanczyk FZ, Taylor PR (2001) Serum hormones and the alcoholbreast cancer association in postmenopausal women. J Natl Cancer Inst 93:710-715.

Eriksson CJP, Fukunaga T, Lindman R (1994) Sex hormone response to alcohol. Nature (Lond.) 369:711.

Feldman HA, Johannes CB, Araujo AB, Mohr BA, Longcope C, McKinlay JB (2001) Low dehydroepiandrosterone and ischemic heart disease in middle-aged men: prospective results from the Massachusetts male aging study. Am J Epidemiol 153:79-89.

Field AE, Colditz GA, Willet WC, Longcope C, McKinlay B (1994) The relation of smoking, age, relative weight, and dietary intake to serum adrenal steroids, sex hormones, and sex hormone-binding globulin in middle-aged men. J Clin Endocrinol Metab 79:1310-1316.

Finney DJ (1964) Statistical Method in Biological Assay. 2nd ed. Charles Griffin, London.

Frias J, Torres JM, Miranda MT, Ruiz E, Ortega E (2002) Effects of acute alcohol intoxication on pituitary-gonadal axis hormones, pituitaryadrenal axis hormones, beta-endorphin and prolactin in human adults of both sexes. Alcohol Alcohol 37:169-173.

Ginsburg ES, Mello NK, Mendelson JH, Barbieri RL, Teoh SK, Rothman M, Gao X, Sholar JW (1996) Effects of alcohol ingestion on estrogens in postmenopausal women. JAMA 276:1747-1751.

Gordon GG, Altman K, Southren L, Rubin E, Lieber CS (1976) Effect of alcohol (ethanol) administration on sex-hormone metabolism in normal men. N Engl J Med 295:793-797.
Grady D, Herrington D, Bittner V, Blumenthal R, Davidson M, Hlatky M, Hsia J, Hulley S, Herd A, Khan S, Newby LK, Waters D, Vittinghoff E, Wenger N, HERS Research Group (2002) Cardiovascular disease outcomes during 6.8 years of hormone therapy: Heart and Estrogen/ Progestin Replacement Study follow-up (HERS III). JAMA 288:49-57.

Grobbee DE, Rimm EB, Keil U, Renaud S (1999) Alcohol and cardiovascular system, in Health Issues Related to Alcohol Consumption (MacDonald EI ed), pp 125-179. ILSI Europe, Blackwell Science, Philadelphia.

Hak AE, Witteman JC, de Jong FH, Geerlings MI, Hofman A, Pols HA (2002) Low levels of endogenous androgens increase the risk of atherosclerosis in elderly men: the Rotterdam study. J Clin Endocrinol Metab 87:3632-3639.

Hankinson SE, Willett WC, Manson JE, Hunter DJ, Colditz GA, Stampfer MJ, Longcope C, Speizer FE (1995) Alcohol, height, and adiposity in relation to estrogen and prolactin levels in postmenopausal women. J Natl Cancer Inst 87:1297-1302.

Hendriks HFJ, Veenstra J, Van Tol A, Groener JEM, Schaafsma G (1998) Moderate doses of alcoholic beverages with dinner and postprandial high density lipoprotein composition. Alcohol Alcohol 33:403-410.

Hendriks HFJ, Veenstra J, Velthuis-te Wierik EJM, Schaafsma G, Kluft C (1994) Effect of moderate dose of alcohol with evening meal on fibrinolytic factors. BMJ 308:1003-1006.

Hodis HN, Mack WJ, Azen SP, Lobo RA, Shoupe D, Mahrer PR, Faxon DP, Cashin-Hemphill L, Sanmarco ME, French WJ, Shook TL, Gaarder TD, Mehra AO, Rabbani R, Sevanian A, Shil AB, Torres M, Vogelbach KH, Selzer RH: Women's Estrogen-Progestin LipidLowering Hormone Atherosclerosis Regression Trial Research Group (2003) Hormone therapy and the progression of coronary-artery atherosclerosis in postmenopausal women. N Engl J Med 349:535-545.

Imhof A, Froehlich M, Brenner H, Boeing H, Pepys MB, Koenig W (2001) Effect of alcohol consumption on systemic markers of inflammation. Lancet 357:763-767.

Ishihara F, Hiramatsu K, Shigematsu S, Aizawa T, Niwa A, Takasu N, Yamada T, Matsuo K (1992) Role of adrenal androgens in the development of arteriosclerosis as judged by pulse wave velocity and calcification of the aorta. Cardiology 80:332-338.

Johannes CB, Stellato RK, Feldman HA, Longcope C, McKinlay JB (1999) Relation of dehydroepidandrosterone and dehydroepiandrosterone sulfate with cardiovascular disease risk factors in women: longitudinal results from the Massachusetts Women's Health Study. J Clin Epidemiol 52:95-103.

Kalmijn S, Launer LJ, Stolk RP, de Jong FH, Pols HA, Hofman A, Breteler MM, Lamberts SW (1998) A prospective study on cortisol, dehydroepiandrosterone sulfate, and cognitive function in the elderly. J Clin Endocrinol Metab 83:3487-3492.

Kiechl S, Willeit J, Bonora E, Schwarz S, Xu Q (2000) No association between dehydroepiandrosterone sulfate and development of atherosclerosis in a prospective population study (Bruneck Study). Arterioscler Thromb Vasc Biol 20:1094-1100.

Kiel DP, Baron JA, Plymate SR, Chute CG (1989) Sex hormones and lipoproteins in men. Am J Med 87:35-39.

Kinosian B, Glick H, Preiss L, Puder KL (1995) Cholesterol and coronary heart disease: predicting risks in men by changes in levels and ratios. J Invest Med 43:443-450.

Koenig W, Sund M, Fröhlich M, Fisher HG, Lowel H, Doring A, Hutchinson WL, Pepys MB (1999) C-Reactive protein, a sensitive marker of inflammation, predicts future risk of coronary heart disease in initially healthy middle-aged men. Circulation 99:237-242.

Lapcík O, Hill M, Hampl R, Wahala K, Adlercreutz H (1998) Identification of isoflavonoids in beer. Steroids 63:14-20.

Leowattana W (2001) DHEA(S): the fountain of youth. J Med Assoc Thai 84:S605-S612.

Manson JE, Hsia J, Johnson KC, Rossouw JE, Assaf AR, Lasser NL, Trevisan M, Black HR, Heckbert SR, Detrano R, Strickland OL, Wo ND, Crouse JR, Stein E, Cushman M, Women's Health Initiative 
Investigators (2003) Estrogen plus progestin and the risk of coronary heart disease. N Engl J Med 349:523-534.

Matthews KA (1992) Myths and realities of the menopause. Psychosom Med 54:1-9.

Mood AM, Graybill FA, Boes DC (1974) Introduction to the Theory of Statistics. 3rd ed. McGraw-Hill, New York.

Mukamal KJ, Kuller LH, Fitzpatrick AL, Longstreth WT, Mittleman MA, Siscovick DS (2003) Prospective study of alcohol consumption and risk of dementia in older adults. JAMA 289:1405-1413.

Nafziger AN, Herrington DM, Bush TL (1991) Dehydroepiandrosterone and dehydroepiandrosterone sulfate: their relation to cardiovascular disease. Epidemiol Rev 13:267-293.

Newcomb PA, Klein R, Klein BE, Haffner S, Mares-Perlman J, Cruickshanks KJ, Marcus PM (1995) Association of dietary and life-style factors with sex hormones in postmenopausal women. Epidemiology 6:318-321.

Okamoto K (1998) Distribution of dehydroepiandrosterone sulfate and relationships between its level and serum levels in a rural Japanese population. J Epidemiol 8:285-291.

Orentreich N, Brind JL, Rizer RL, Vogelman JH (1984) Age changes and sex differences in serum dehydroandrosterone sulfate concentrations throughout adulthood. J Clin Endocrinol Metab 59:551-555.

Pettersson P, Ellsinger BM, Sjoberg C, Bjorntorp P (1990) Fat distribution and steroid hormones in women with alcohol abuse. J Intern Med 228:311-316

Ravaglia G, Forti P, Maioli F, Sacchetti L, Nativio V, Scali CR, Mariani E, Zanardi V, Stefanini A, Macini PL (2002) Dehydroepiandrosteronesulfate serum levels and common age-related diseases: results from a cross-sectional Italian study of a general elderly population. Exp Gerontol 37:701-712.

Reichman ME, Judd JT, Longcope C, Schatzkin A, Clevidence BA, Nair PP, Campbell WS, Taylor PR (1993) Effects of alcohol consumption on plasma and urinary hormone concentrations in premenopausal women. J Natl Cancer Inst 85:722-727.

Ruitenberg A, van Swieten JC, Witteman JC, Mehta KM, van Duijn CM, Hofman A, Breteler MM (2002) Alcohol consumption and risk of dementia: the Rotterdam Study. Lancet 359:281-286.

Rumpler WV, Rhodes DG, Baer DJ, Conway JM, Seale JL (1996) Energy value of moderate alcohol consumption by humans. Am J Clin Nutr 64:108-114.

Sarkola T, Adlercreutz H, Heinonen S, Eriksson CJP (2001) Alcohol intake, androgen and glucocorticoid steroids in premenopausal women using oral contraceptives: an interventional study. J Steroid Biochem Mol Biol 78:157-165.

Schofield WN (1985) Predicting basal metabolic rate, new standards and review of previous work. Hum Nutr Clin Nutr 39:S5-S41.

Sierksma A, Sarkola T, Eriksson CJP, Hendriks HFJ (2002a) Effects of moderate alcohol consumption on plasma hormone levels in healthy middle-aged men. Alcohol Research 7:235-238.

Sierksma A, Van der Gaag MS, Kluft C, Hendriks HFJ (2002b) Moderate alcohol consumption reduces plasma $\mathrm{C}$-reactive protein and fibrinogen levels: a randomized, diet-controlled intervention study. Eur J Clin Nutr 56:1130-1136.
Stampfer MJ, Colditz GA, Willett WC, Speizer FE, Hennekens CH (1988) A prospective study of moderate alcohol consumption and the risk of coronary disease and stroke in women. N Engl J Med 319:267-273.

Tamimi R, Mucci LA, Spanos E, Lagiou A, Benetou V, Trichopoulos D (2001) Testosterone and oestradiol in relation to tobacco smoking, body mass index, energy consumption and nutrient intake among adult men. Eur J Cancer Prev 10:275-280.

Thomas HV, Reeves GK, Key TJ (1997) Endogenous estrogen and postmenopausal breast cancer: a quantitative review. Cancer Causes Control 8:922-928.

Ukkola O, Gagnon J, Rankinen T, Thompson PA, Hong Y, Leon AS, Rao DC, Skinner JS, Wilmore JH, Bouchard C (2001) Age, body mass index, race and other determinants of steroid hormone variability The HERITAGE Family Study. Eur J Endocrinol 145:1-9.

Välimäki MJ, Laitinen K, Tiitinen A, Steman UH, Ylöstalo P (1995) Gonadal function and morphology in non-cirrhotic female alcoholics: a controlled study with hormone measurements and ultrasonography. Acta Obstet Gynecol Scand 74:462-466.

Välimäki M, Pelkonen R, Härkönen M, Tuomala P, Koistinen P, Roine R, Ylikahri R (1990) Pituitary-gonadal hormones and adrenal androgens in non-cirrhotic female alcoholics after cessation of alcohol intake. Eur J Clin Invest 20:177-181.

Van den Beld AW, Bots ML, Janssen JAMLL, Pols HAP, Lamberts SWJ, Grobbee DE (2003) Endogenous hormones and carotid atherosclerosis in elderly men. Am J Epidemiol 157:25-31.

Van der Gaag MS, Sierksma A, Schaafsma G, Van Tol A, GeelhoedMieras T, Bakker M, Hendriks HFJ (2000) Moderate alcohol consumption and changes in postprandial lipoproteins of premenopausal and postmenopausal women: a diet-controlled, randomized intervention study. J Womens Health Gend Based Med 9:607-616.

Van der Gaag MS, Van Tol A, Scheek LM, James RW, Urgert R, Schaafsma G, Hendriks HFJ (1999) Daily moderate alcohol consumption increases serum paraoxonase activity; a diet-controlled, randomised intervention study in middle-aged men. Atherosclerosis 147:405410

Van Thiel DH, Lester R (1979) The effect of chronic alcohol abuse on sexual function. Clin Endocrinol Metab 8:499-510.

Watson RR, Huls A, Araghinikuam M, Chung S (1996) Dehydroepiandrosterone and diseases of aging. Drugs Aging 9:274-291.

Westerterp KR (1996) Effect of moderate alcohol consumption on energy expenditure. Alcohol Research 1:187-189.

Ylikahri R, Huttunen M, Härkönen M, Seuderling U, Onikki S, Karonen SL, Adlercreutz H (1974) Low plasma testosterone values in men during hangover. J Steroid Biochem 5:655-658.

Zmuda JM, Cauley JA, Kriska A, Glynn NW, Gutai JP, Kuller LH (1997) Longitudinal relation between endogenous testosterone and cardiovascular disease risk factors in middle-aged men. A 13-year follow-up of former Multiple Risk Factor Intervention Trial participants. Am J Epidemiol 146:609-617.

Zumoff B, Rosenfeld RS, Strain GW, Levin J, Fukushima DK (1980) Sex differences in the twenty-four-hour mean plasma concentrations of dehydroisoandrosterone (DHA) and dehydroisoandrosterone (DHAS) and DHA to DHAS ratio in normal adults. J Clin Endocrinol Metab 51:330-333. 